\title{
A Ponte de Pedra, travessia para outros mundos
}

\author{
Adriana Werneck Regina ${ }^{1}$
}

Introdução

A Chapada dos Parecis, no Noroeste do Mato Grosso, é constituinte do divisor das bacias amazônica e platina, e identifica geograficamente a região do Rio Sacuriuiná, onde há a Ponte de Pedra, o lugar de origem do povo Haliti. A narrativa mítica que se apresenta abaixo sobre a origem desse povo foi contada por um homem, na língua portuguesa, na sua casa, no dia vinte e três de fevereiro de mil novecentos e noventa e seis (23/02/1996), na Aldeia Seringal, na Terra Indígena (T.I.) Paresi, quando lá ele morava. Entretanto, é importante sublinhar que o domínio da língua portuguesa pelas geraçôes atuais coexiste com a vigência da língua materna, classificada como pertencente à família linguística Aruak. Na versão registrada aqui, reincidem os fenômenos relatados noutras versōes ouvidas quando com eles morei.

Antes, esclareço que estive inserida num projeto de intervenção indigenista junto ao povo Paresi entre 1995 e 1997, através da Operação Amazônia Nativa (OPAN), uma organização não governamental sediada em Cuiabá, Mato Grosso, Brasil. Por registrar em diários de campo as experiências vividas

1 Graduada em Ciências Sociais, mestranda em Educação Ambiental do Instituto de Educação (IE) da Universidade Federal de Mato Grosso (UFMT) e indigenista. E-mail: dridriwr@gmail.com. Celular: (65) 9252-2900 
na relação com as famílias desse povo, foi possível construir estas reflexões no campo da Antropologia. Muitas informaçôes aqui contidas vieram da interação com pessoas Haliti, e outras a partir da sistematização de informaçóes extraídas da pesquisa bibliográfica. Exposto isso, compartilho a narrativa mítica e as interpretaçóes construídas, reconhecendo que este texto pode ser revisitado e aberto para uma continuidade dele, incorporando outras experiências históricas na trajetória da interação do povo Haliti com o não indígena.

\section{A Ponte de Pedra, travessia para outros mundos}

Sobre a terra viviam Deus e seus filhos. Era um lugar muito bonito e florido. O povo Paresi vivia embaixo da terra, e nem sequer os deuses sabiam da existência dele. Os Haliti viviam como tatus e se alimentavam de terra e fruta e faziam muitas festas. Um dia, um filho de Deus foi para o rio e ouviu um barulhão vindo da terra. Eram os sons da festa embaixo da terra. Esse filho ficou assustado, não sabia que barulho era aquele. Ficou com medo e saiu correndo para avisar os outros. Os deuses acharam esse medo sem lógica, porque conheciam tudo o que existia no mundo, então, aquele barulho jamais poderia ser causado por algo desconhecido. Disseram, então, que era barulho dos bichos. Dai, os deuses foram ao local do barulho e soltaram um raio que caiu numa pedra. Foi um estouro de onde vinha o barulho, como se fosse uma bomba, e acabou formando um buraco na pedra. Do mundo subterrâneo saiu um passarinho. Ele voou e conheceu aquele campo todo florido e perfumado. Ficou tão encantado que levou três tipos de flores para mostrar aos habitantes que viviam embaixo da terra. Quando ele voltou para esse lugar através do buraco da pedra, ele ficou triste. Afinal, eles viveram tanto tempo sem saber desse lugar do campo que era tâo bonito. O pajé que sempre falou que sabia de todas as coisas nunca tinha contado sobre isso. $O$ pajé reagiu e resistiu em acreditar nesse outro lugar, pois ele sabia de tudo mesmo. Dai, o passarinho mostrou as três flores e os levou para conhecer esse lugar. Foi quando eles sairram da pedra e passaram a viver em cima da terra. Quando isso aconteceu, eles tentaram segurar os seres que causavam doenças e misérias. Mas eles disseram que queriam ir também e que só atacariam as pessoas ruins, mas o que tem acontecido na realidade é que eles estão atacando todos, inclusive 
pessoas boas. Ai, foi quando passaram a viver nesse lugar que eles modificaram a alimentação deles. Eles não comiam mandioca antes. E nessa terra de cima, tudo tem dono. Tem o dono do rio e de tudo o que está ligado ao rio. Tem o dono da mata, da mandioca, enfim, de tudo. Esses donos são espíritos que podem ser bons ou maus, dependendo do comportamento dos indios. E isso já aconteceu com um caçador e com outro indio que foram pescar e não ofereceram para ele porque não acreditaram que tinha dono e não obedeceram aos donos quando eles apareceram exigindo que fizessem oferta, por isso tudo tem que ofertar antes de comer.

No início dessa narrativa mítica, são apresentados dois mundos como realidades autônomas, separadas e ignorantes uma da outra. Revela-se um início sem uma origem comum, ao contrário, um primórdio descentrado, relacionado à coexistência temporal de contextos socioculturais e ecológicos diferentes. Podemos correlacionar esse evento mítico à análise de Derrida (2002) sobre a narrativa bíblica da Torre de Babel. O horizonte desse autor não é orientado à concepção de uma origem primordial atribuída a uma sociedade humana, tida como fonte da diversidade cultural e linguística entre os povos, o que retrataria a anterioridade marcada pela comunicaçáo por uma língua única e a homogeneidade cultural que teria sido rompida pela atual condição de heterogeneidade cultural e linguística. $\mathrm{O}$ autor, ao contrário, reconhece que a relação entre as diversas línguas é, de fato, marcada pela diferença, e que esta não tem como pressuposto a mesma referência original, desconstruindo o parentesco entre as línguas pautado numa ascendência única.

O modo de relação entre as várias coletividades humanas, sob o viés desse paradigma da origem comum, é marcado pela crença de que tudo é traduzível, isto é, que todos os sentidos e significados têm seus correspondentes equivalentes em todas as realidades. Retrata a afirmação de um referente homogêneo e universal, que constitui a base para todas as culturas representarem. A ideia do relativismo cultural opera com esse princípio, em que a diferença representacional consiste no modelo de um mundo objetivado universalmente.

Derrida (2002), ao contrário, contempla o evento da intraduzibilidade, admitindo a possibilidade de realidades construídas com diversidade de re- 
ferentes e simbolizaçóes, revelando universos semânticos diferenciados. Dar sentido às experiências envolve um ponto de vista de mundo que precisa ser considerado na busca de uma tradução. $\mathrm{O}$ mundo não é único e estável, há diversas possibilidades de relaçóes com ele. Retomando as reflexóes de Benjamin (2001), o original é apreendido como um devir e não como um passado fixo, central e estável. Perceber a falta de ressonância de significado e sentido idêntico em outro mundo provoca a impossibilidade de uma tradução como cópia, pois não existe um correspondente semelhante imprescindível no outro, as realidades não são circunscritas por um reflexo recíproco. Procurar nos ver no outro implica um exílio de nosso contexto cultural e linguístico, engendrando uma relação de estranhamento em relação a este. Nosso próprio ponto de vista de mundo torna-se palco de reflexão, decodificação e interpretação na tradução do “outro". Conforme Derrida (2002), essa relação entre duas línguas é como semear outra língua, à medida que a condição do intraduzível se impõe, isto é, o desencontro de equivalentes iguais. É criada, então, outra obra que não é idêntica à original, tampouco ao contexto sociocultural e linguístico do tradutor. Novos sentidos, significados e ideias são alvos de pensamento e interpretaçáo, a partir de elementos inscritos nos dois campos semânticos envolvidos. Há uma modificação do original que resguarda as mediaçóes do tradutor e do universo "traduzido", gerando um original renovado, pautado na transgressão dos limites dos dois mundos contemplados, que se complementam e interagem. Isso possibilita a alteridade entre culturas e línguas, há um engrandecimento, uma expansão de ambas as realidades envolvidas, quando são igualmente mediadoras com seus sentidos, significados e perspectivas de mundo. Nesse sentido, o original é um devir, um encontro de mundos diferentes orientados à expansão destes, a partir da interação numa ponte que liga realidades antes separadas e isoladas:

[...] se quisermos juntar de novo os cacos de um vaso, estes têm de corresponder uns aos outros, sem serem todavia necessariamente iguais quanto às suas ínfimas particularidades, também a tradução, em vez de imitar o original para se aparentar a ele, deve insinuar-se com amor nas mais ínfimas particularidades tanto dos modos do «querer dizer» original como na sua própria língua, isto de maneira a juntá-las como se fossem cacos de um vaso, para que depois de a juntar elas nos deixem reconhecer uma Língua mais ampla que as abranja a ambas (Benjamin, 2001, p.41). 
É nesse paradigma de um original voltado ao devir, à alteraçáo das realidades envolvidas, que se insere esse mito, quando mundos originalmente distintos e separados se encontram e se descobrem para o devir de alteraçóes na Ponte de Pedra.

É enfatizado que os deuses viventes sobre a terra e o pajé do mundo sob a terra assemelham-se quanto à qualidade da onisciência, e são igualmente traídos pela experiência da descoberta de outras coletividades humanas.

A manifestação de uma festa produziu um som que se propagou, tornando-se audível no mundo em cima da terra num momento em que, por acaso, $\mathrm{o}$ filho de um deus estava na redondeza e o ouviu. $\mathrm{O}$ barulho náo tinha ressonância com os sons já conhecidos, e desse estranhamento houve a possibilidade do conhecimento de outro mundo.

Isso reforça a ideia do devir, associada à noção de um mundo inacabado, em que a incompletude é a condição deste. Novamente Benjamin (2001) é evocado, pois o mundo nunca pode ser reproduzido de forma idêntica ao original, assumindo um caráter transcendental e atemporal. Esse autor afirma que toda obra detém um desejo de ser traduzida, quer dizer algo, o que nos remete ao encontro de realidades diferentes:

[...] nenhum dado do conhecimento pode ser ou ter pretensóes a ser objetivo quando se contenta em reproduzir o real, e do mesmo modo também nenhuma tradução será viável se aspirar essencialmente a ser uma reproduçáo parecida ou semelhante ao original. Isto porque o original se modifica necessariamente na sua «sobrevivência», nome que seria impróprio se não indicasse a metamorfose e renovação de algo com vida (Benjamin, 2001, p.39).

A condição do isolamento é a imperfeição; na tradução há relação, e nesta há a morte do original. Como dito, ele não existirá mais de forma idêntica, pois há transformação decorrente da relaçáo com outro modo de significar. Entretanto, há a sobrevida da obra, pois ela não é superada, assegurando uma relaçáo de continuidade entre o original e o modificado. Nessa perspectiva, Benjamin (2001) reconhece a agência de contextos culturais, políticos, econômicos, linguísticos e de subjetividades nos modos de significar, retratando a historicidade operante na produção e na tradução de obras. É transgredida a ideia de uma essência imutável do original, elevando 
a historicidade como incidente. Todas as realidades culturais e linguísticas, inclusive aquelas retratadas nesse mito, demonstram compartilhar a submissão a experiências inusitadas, imprevisíveis, casuais, geradoras de um dinamismo confundido pelo evento das alteraçóes dos modos de existir. Inexiste uma essência imutável imune de historicidade.

Procurar na subjetividade recém-nascida e não na própria vida da língua e das suas obras a essência tanto dessas metamorfoses como da constância dos significados seria, como confessaria até o psicologismo mais crasso, confundir a base de uma coisa com a sua essência; ou, agora em palavras mais rigorosas, isso significaria nada menos que negar, por incapacidade de raciocínio, um dos mais poderosos e frutíferos processos históricos. [...] do mesmo modo que o significado e a camada sonora de uma poesia se modificam completamente com o decurso dos séculos também se modifica a própria língua materna do tradutor. Sim, enquanto a palavra do poeta sobrevive na sua própria língua as traduçôes de grande valor também estão destinadas por um lado a contribuir para o crescimento e engrandecimento da sua língua e por outro a afundar-se entre as renovaçóes que surgem (Benjamin, 2001, p.39).

É interessante reconhecer no mito o evento do som que se propagou como se estivesse desejando ser ouvido e descoberto. Junto à disposiçáo de ser ouvido, há também a de tentar ser decodificado, a partir do estranhamento pelos deuses, bem como o passarinho que quer transgredir sua fronteira, arriscando-se a sair pelo buraco. $\mathrm{O}$ essencialismo do mundo dos deuses e do pajé e de seus conterrâneos foi traído; o mundo não poderá mais ser igual. A perpetuação da condição de separação entre os dois universos foi finita e interrompida por um evento que alterou ambas as realidades. Esse evento só se configurou como tal por perceber algo desconhecido que despertou o desejo de aproximação e conhecimento.

Steiner (2000) é relembrado quando afirma que a tradução entre línguas distintas é uma aventura no encontro com outro mundo simbólico, o que permite o contato com novas experiências que produzem sentido e significado. O intraduzível é uma possibilidade existente, retratando a falta de ressonância entre os contextos semântico e cognitivo envolvidos. $\mathrm{O}$ autor reconhece que há a tendência a domesticar o inusitado, isto é, a atribuir sentido a ele, validando as classificaçôes já existentes, visando a uma apro- 
ximação, produzindo uma semelhança. Os deuses pensaram que o barulho ouvido era um bicho, mesmo assim estranharam e se arriscaram a descobrir o que era, lançando um raio. Mas a alteração é inevitável nesse empreendimento. Apropriar-se do outro é um permanente risco, pois exige o desvio da sua referência para abarcar a manifestação do diferente. O resultado da tradução não resultará na semelhança idêntica com a classificação inscrita precedente. Haverá expansão, transgredindo a tendência do ideal de uma reprodução igual:

[...] our own being is modified by each occurrence of comprehensive appropriation. No language, no traditional symbolic set or cultural ensemble imports without risk of being transformed (Steiner, 2000, p.188).

O raio lançado por um deus criou um buraco que, na história, foi convertido em passagem por onde saíram os viventes sob a terra. Tem correlação simbólica com a própria identificação geográfica dada pelos Haliti ao seu lugar de origem: Ponte de Pedra. O buraco assume, então, o papel de uma ponte que liga dois mundos, sendo decisiva a instauração de uma continuidade entre eles, associada à extensão e ao engrandecimento de ambos.

O passarinho foi o primeiro a sair e a motivar os Haliti para conhecer o outro lado. D; evido ao seu encantamento pela beleza do mundo fora da pedra, até trouxe flores para ilustrar o que viu. Vale a pena registrar um fragmento de outra versão ouvida da mesma história, contada por um senhor de uma aldeia vizinha chamada Novo Seringal: quando sairam, viram aquela beleza toda e sentiram os perfumes das flores. Esse fragmento retrata o contato com novos elementos a serem incorporados e submetidos aos sentidos de percepção, em que o ver e o cheirar foram valorizados na apreensão dessa nova realidade. Demonstra também que o passarinho é percebido como sujeito dotado de intencionalidade e ação, em interação com os Haliti.

Isso nos remete a Latour $(1989,1994)$, considerando sua reflexão sobre a realidade ser fruto da interação entre agentes humanos e não humanos, em que estes têm o mesmo status quanto à expressão de enunciados. $\mathrm{O}$ autor transgride a ideia de atribuir autoria única aos humanos no modo como uma sociedade se configura, validando-a como domesticação de elementos naturais, passivos, a serviço da intenção e reflexão humanas. Latour (1989, 1994) reconhece que o modo de relação do homem com a natureza engendra 
uma sociedade que é ela mesma essa interação entre humanos e não humanos. Questiona a possibilidade de estabelecer fronteiras, delimitando o que é tecnologia, sociedade e natureza:

[...] il faut formuler symétriquement les mêmes arguments au sujet de la société et au sujet de la nature. [...] Nous avons alors besoin d'une règle de symétrie qui n'atribue pas à la société des privilèges que nous avons refusés à la nature. [...] Nous devons considérer de façon symétrique les efforts pour recruter et contrôler les ressources humaines et non humaines (Latour, 1989, p. 235).

No mito, tal situação se inscreve quando há a possibilidade de comunicação entre o povo Haliti e o passarinho, e quando a intencionalidade da ave desencadeia uma experiência que é valorizada e considerada para a reflexão e a ação do povo Haliti. Essa relação entre agentes humanos e não humanos desencadeia a possibilidade de uma nova aventura, promovendo a inserção de todos eles numa mesma rede de relação social que abrange, por sua vez, os deuses. Esses últimos impóem-se como donos ${ }^{1}$ de tudo o que há no mundo fora da pedra. Manifestam-se como "sobrenaturais" os donos da mandioca, dos animais de caça e da pesca, conforme relatado nessa narrativa.

$\mathrm{Na}$ relação do povo Haliti com o que classificamos como fauna e flora, há a mediação desses seres sobrenaturais, os donos, apreendidos como outros. A natureza não é uma categoria isolada. Do ponto de vista do povo Haliti, há uma relação social com os deuses (usando o termo adotado pelo narrador) que incide na relação com a fauna e a flora. É expressa, contudo, uma interação entre humanos, animais, plantas, peixes e seres sobrenaturais de caráter social.

A natureza é parte da rede de relação social e, portanto, não existe enquanto uma categoria autônoma e pura. $\mathrm{O}$ conjunto das práticas sociais entre o povo Haliti e os outros não humanos revela uma socialidade expandida, desencadeada pelo encontro de mundos. Nesse sentido, vê-se correspondência com Latour (1989, 1994), que nega a existência da sociedade e da natureza como categorias purificadas.

1 Está sendo adotado o termo "dono”, repetindo a tradução dada pelos Pareci. 
O mundo em cima da terra é alterado e transformado. Inicia-se a alimentação com mandioca e, conforme o mito, o cultivo dessa raiz na roça, na prática, é acompanhado de uma comunicação com o dono da mandioca, em que o canto é um recurso expressivo.

Na casa onde morava o cacique da Aldeia Seringal, nesse referido período de minha convivência, havia uma flecha sagrada, sem ponta e ornamentada, denominada korehete, presa num dos esteios, lugar em que permanentemente tem cabaças grandes cheias de zacalo, espécie de xixa de mandioca, como oferta aos donos, feita por trabalho coletivo das mulheres envolvendo esposa e filhas. A taquara utilizada para fazer a flecha foi encontrada pelo cacique no lugar indicado no seu sonho, e conforme ele me disse, havia somente uma reservada para ele. Os caçadores sempre traziam suas caças para a região dessa flecha, onde a distribuição da carne para as famílias era antecedida por uma canção específica, feita por um benzedor, e que consistia numa comunicação com o dono do animal caçado.

Imprime-se na flecha sagrada um caráter híbrido, em que a ação do cacique mistura-se a um vegetal disponibilizado por um ser sobrenatural, que comunicou a ele o lugar geográfico de sua extração através do sonho. Além disso, abrange outras coletividades, quando o que promoveu a posição de amur $i^{2}$ a esse cacique envolve a sua intenção de abrir uma nova aldeia, à custa da mobilizaçáo de todos seus genros para tanto. Esse objeto está intimamente relacionado ao mito, pois a flecha existe, porque o povo Haliti foi inserido no mundo fora da pedra. Ela é parte dessa mediação humano-sobrenatural, significativa nessa socialização no mundo sobre a terra. É um híbrido, um objeto construído por agências diversas. Paralelamente às discussóes de Latour (1989, 1994), podemos interpretar a flecha sagrada como envolvendo um conjunto de coletividades diversas em torno da elevaçáo do cacique, da articulação dele junto aos seus genros para a caça, do benzedor, das famílias que consumirão a xixa produzida como oferta às entidades sobrenaturais e da mobilização para a abertura da roça.

Compreender a flecha sagrada requer considerar esses diversos eventos dispersos no tempo e no espaço, os quais envolvem humanos, vegetais, seres sobrenaturais e animais. Contudo, são destruídas quaisquer perspectivas de interpretar o fenômeno sob uma lógica mecanicista que atribui valor de

2 Traduzido pelos Pareci como "cacique". 
causa e efeito às variáveis, selecionando um evento como referência original, fixa e única.

De acordo com Latour (1989, 1994), a interpretação de uma informação exige compreendê-la dentro de uma rede de relação social que contempla tal dispersão de tempo, espaço e coletividades, rompendo com a ideia de uma autoria individual responsável pelo evento, quando o coletivo se sobrepóe. Nesse sentido, não há cópia de um original, porque há produção coletiva, desfazendo progressivamente a possibilidade de eleger um centro como referência, uma vez que diversos eventos circulam e transitam nesse histórico de que diversas coletividades participam.

Embora Haliti seja um nome que se refere à unidade de uma coletividade, é sabido que dentro dela há outras referências de unidades sociais que assumem valor enquanto identidade de grupo, e que são mobilizadas para demarcar diferenças e distinçôes em muitos contextos de caráter político e geográfico. Kozarene, Waimaré, Kaziniti, Warere e Kawali são nomes desses grupos. No mito, é explicada a origem deles como nomeação dos descendentes dos irmáos que atravessaram a ponte para o mundo em cima da terra.

Relacionado a esse mito, ouvi de muitas pessoas do povo Haliti que o primeiro a sair da pedra foi Wazaré, o irmão mais velho. Depois foi Kamazo, cujos filhos são Kozarene, em seguida Zakálo e Zalóya que, casados com uma mesma mulher, tiveram os filhos Waimaré. Os Kaziniti são filhos de Zaolare. De Kono, descendem os Warere, e os Kwali vêm de Tahoe. Por último, saiu Kamaihi 'ye, que não deixou filhos.

A Chapada dos Parecis é interpretada como criação de Wazare, o irmáo mais velho, que foi traduzido como um deus por pessoas que relataram tal mito. Atribui-se a ele a origem de todas as cabeceiras, bem como a distribuição geográfica dos referidos grupos em territórios definidos.

Aos Kaziniti foi reservado o vale do Rio Sumidouro, afluente do Rio Arinos, espalhando-se pelas cabeceiras do Rio Zutiakurêinazá (Sepotuba) e Sucuriuiná (Rondon, 1947).

Aos Kozarene foi dada a região do divisor das águas dos rios Koterekôiná (Juba) - afluente do Sepotuba -, Cabaçal, Jauru, Guaporé, Verde, Sauêruiná (Papagaio), Zolaháruiná (Buriti), Anáuiná(Juruena) e Sucuriuiná (ibidem).

Os Waimare foram situados ao longo dos rios Timalatia (Sacre) e Tahuruiná (Verde), cuja nascente é constituída pelas cabeceiras Yanakakerê-suê (da Taquara) e Uptezare-suê (Preta) (ibidem). 
É sabido que os rios Verde, Sacre, Papagaio e Buriti formam os rios Tapajós e Madeira, da Bacia Amazônica; e que os rios Guaporé, Sepotuba, Cabaçal e Jauru, o Rio Paraguai, da Bacia Platina.

A alteração é um evento associado à ponte, a qual disponibilizou a relação entre as realidades antes separadas, configurando a alteridade como um paradigma que se perpetua nessas narrativas e se inscreve no presente como um fluxo mítico. A topografia da região da Chapada dos Parecis imprime a agência de um Haliti, testemunhando sua participação nesse mundo do qual seu povo faz parte, quando com ele passou a se relacionar.

Todo agente envolvido numa relação tem agência e realiza a sua mediação. A inserção do povo Haliti no mundo sobre a terra jamais seria de qualidade neutra e invisível. Trata-se de uma relação em que a expansão dos mundos envolvidos é um risco e um ganho a ser experimentado. O fluxo de vivências inscrito no mito demonstra que houve uma expansão no mundo dos deuses e do povo Haliti. A criação de Wazare pode ser compreendida como um risco assumido pelos seres sobrenaturais. A noção de um original imutável e eterno é refratária na concepção do mundo que se expressa.

Há continuidade de alteraçóes no mundo, assim como se revela uma relação de continuidade entre a realidade e o mito, o que torna duvidosa a possibilidade de estabelecer uma fronteira entre eles.

Nos primeiros dez anos do século XX, a comissão de Cândido Mariano Rondon percorreu os rios Sumidouro, Sangue, Cravari, Timalatia (Sacre), Buriti, Sauêruiná (Papagaio), Juruena e Sacuriuiná, estabelecendo seus primeiros contatos com os grupos Waimaré, Kaziniti e com alguns Kozarene do povo haliti (Rondon, 1947; Machado, 1994).

Retomando Latour (1989, 1994), na rede de relaçóes sociais do povo Haliti flui a interconexão com outras coletividades que também se constituíram como agentes ativos.

Sabe-se que o Projeto Linhas Telegráficas e Estratégicas de Mato Grosso ao Amazonas foi concebido no século XIX para marcar fronteira com Bolívia e Paraguai. Entretanto, foi executado pela Comissão Rondon como estratégia militar para consolidar fronteiras, no contexto do mercado internacional da borracha. De outro lado, teve o papel também de conhecer a geografia, a mineralogia, a botânica e a etnografia (Machado, 1994, p. 258). No caminho da expedição de Rondon, na primeira década do século passado, havia a presença de vários barracóes com pessoas do povo Haliti vendendo poaia 
e borracha, denunciando o contato precedente com os seringueiros ocorrido nessa mesma década (Costa, 1985). Importante salvaguardar que os grupos em relação com os seringueiros nessa época eram os Kaziniti e Waimaré, abrangendo as regióes dos rios Sepotuba, Verde, Sacre e Papagaio. Segundo Costa (1985), ambos os grupos estavam também envolvidos em atividades de mineração, atuando como guias delas, além de terem sido absorvidos como mão de obra na exploração e no comércio da borracha, bem como escravizados por bandeirantes.

Há registros de relação com o não índio já desde 1759, conforme relato do bandeirante Antônio Pires Campos. Portanto, não foi a Comissão Rondon que propiciou a interconexáo de grupos do povo Haliti com a rede social do contexto cultural não indígena, mas foi ela quem provocou uma transformação na configuração da territorialidade dos grupos fundada por Wazare, pois eles, enquanto unidades sociais referidas a um espaço territorial específico, já não existiam no final da década de 30 do século XX (Rondon, 1947).

Na região da Ponte de Pedra onde viviam os Kaziniti, foi instalada a $1^{a}$ sede da linha telegráfica, em 1907 (Machado, 1994, p. 260). Utiariti foi outro lugar em que Rondon instalou uma base telegráfica e uma escola. Nessa última, viviam os Waimare. Elas foram concebidas como focos de concentração, intencionando atrair pessoas do povo Haliti, deslocando-as das atividades extrativistas de poaia e seringa, avaliadas como exploratórias por Rondon (Machado, 1994, p. 261).

Os amuri, traduzidos como chefes pelos militares, transformaram-se em guias de expedição da Comissão (Machado, 1994); já os demais, tornaram-se trabalhadores nas linhas telegráficas instaladas e aprendizes na escola.

Ao longo dos anos vinte, a concentração nas bases telegráficas intensificou a mistura dos grupos Kozarene, Kaziniti e Waimaré, associada à evasão das aldeias existentes na época, desfigurando aquela distribuição social geográfica agenciada por Wazare.

Desde 1946, após a falência do Projeto das Linhas Telegráficas, a escola em Utiariti passou a ser administrada pela Missão Anchieta - ligada à Congregação dos Jesuítas.

A pedagogia etnocêntrica consolidou-se, os filhos foram separados de seus pais como estratégia de rompimento do ensino e aprendizagem de outros modos de viver, herdados e recriados no contexto cultural Haliti. Até as visitas de parentes e a fala na língua materna foram censuradas à custa de 
castigos físicos. Crianças das etnias Irantxe, Rikbaktsa e de outras, localizadas no Noroeste de Mato Grosso, foram deslocadas para essa escola, sendo submetidas ao uso de uniforme, ao corte de cabelo padronizado, enfim, à educação em sistema de internato. Casamentos interétnicos eram valorizados a fim de fortalecer a descontinuidade dos conhecimentos, linguagens e visóes de mundo de seus ancestrais (Machado, 1994; Costa, 1985).

O projeto pedagógico e político oficial, desde a Comissão Rondon até a Missão Anchieta, era integrar os indígenas à civilização nacional, transformando as aldeias e aldeamentos em cidades. Sob a ideologia positivista, almejava-se desconstruir a pluralidade cultural e linguística das diversas sociedades humanas a favor de uma unidade de Estado-Nação. As pessoas das diversas etnias deveriam ser transformadas em contribuintes na demarcação de fronteiras, e concebidas enquanto integrantes da mesma sociedade civil e habitantes do território de uma sociedade nacional brasileira.

As reflexóes de Susan Bassnett e Harish Trived (1999), bem como as de Paula Rubel e Abraham Sosmam (2003), encontram ressonância com esses eventos históricos. Entre os Haliti, a Comissão Rondon e a Missão Anchieta havia uma relação assimétrica marcada por desigualdade de poder. Era intencionado forjar uma origem cultural e linguística para esse povo, incorporando-o ao Estado-Nação. Almejava-se impor os valores, as ideias, os conceitos, as técnicas de agricultura e pecuária, os sistemas de ensino e aprendizagem, padróes de alimentação e outras condiçóes de vida social atreladas ao modelo cultural não indígena europeu, herdado do colonialismo. As diferenças na maneira de pensar, sentir e agir encontradas no caminho da Comissão Rondon e da Missão Anchieta foram submetidas a um empreendimento domesticador, orientado à produção da semelhança.

A Ponte de Pedra converteu-se em palco de uma política cultural colonizadora quando quis tornar o mundo Haliti uma extensão da sociedade nacional não indígena, universalizando os modos de significar e interpretar a realidade, bem como de interagir com ela. Configurou-se a tentativa de controlar o outro e apropriar-se dele, desvalorizando as diferenças e a alteridade.

De acordo com Bassnett \& Trived (1999) e Rubel \& Rosman (2003), identifica-se a ideologia da produção de semelhança, dando visibilidade à política, à filosofia, à teologia, à economia e à sociologia das sociedades industriais, validando um ponto de vista semântico. A qualidade de relação é 
neutralizada, quando a manifestação de diferenças linguísticas e culturais do outro é motivo de repressão, opressão e julgamento negativo, enfatizando a desigualdade como condiçáo relacional e forjando uma identidade cultural e linguística. Há a ideia de reproduzir de forma idêntica o original, elegendo um termo como centro. Assad (1986) e Niranjana (1992) reiteram a ideia de que a ideologia é agência, conferindo caráter político em toda relação, transgredindo com isso a noção de uma neutralidade. A não afirmação da diferença assume, contudo, uma posição política.

No início dos anos 70 do século XX, a escola de Utiariti foi desativada, houve revisão do Concílio do Vaticano, nos anos 60, e a aculturação passou a ser qualificada negativamente (Costa , 1985; Machado, 1994).

Esse evento é paralelo ao contexto da política de integração nacional do governo militar brasileiro no período desenvolvimentista. Nos anos 70 foram implementadas as rodovias federais, fomentando a ocupação nas regióes do Centro-Oeste e Amazonas, concebidas como partes inexploradas e despovoadas da sociedade nacional brasileira. Migrações da populaçáo do sudeste e do sul foram incentivadas e subsidiadas para tais regióes com a finalidade de difundir o agronegócio, a pecuária e outras frentes econômicas extrativistas (minério, madeira etc.). O POLOCENTRO é um dos programas governamentais que retrata isso, bem como a BR-364 (Cuiabá-MT - Porto Velho-RO).

A condição física da região criada por Wazare foi alterada, impondo-se o desmatamento acelerado, progressivo e descontrolado desencadeado pelo agronegócio da soja, da cana-de-açúcar, da pecuária extensiva e do extrativismo madeireiro.

Com o fechamento da escola de Utiariti, no início dos anos setenta, integrantes da Missão Anchieta fixaram-se em algumas aldeias, morando com famílias do povo Haliti. Os padres jesuítas converteram-se em aliados do povo na luta pela demarcação territorial, na medida em que se expandia a ocupação fundiária, expropriando a terra dos grupos étnicos dessa regiáo de Mato Grosso. Inclusive, leigos foram recrutados compondo equipes para uma ação política em defesa dos direitos indígenas a terra e a um modo diferente de se relacionar com o mundo.

Foi instaurado um conflito territorial que, para os Haliti em especial, resultou na transformação da condição de viver no mundo sobre a terra. Aconteceu uma enorme redução do espaço físico para viverem em comuni- 
dades. Foram demarcadas terras indígenas de modo descontínuo, separadas entre si por fazendas, cidades e estradas que na região se consolidaram. Atualmente, têm demarcação das terras indígenas Estivadinho, Figueiras, Juininha, Pareci, Rio Formoso, Utiariti e a delimitação de Capitão Marcos e Estação Rondon. Eu tive a oportunidade de conviver com famílias residentes de algumas aldeias nas Terras Indígenas Pareci e Utiariti.

Nesse percurso conflituoso, ao longo dos anos 80 e 90 do século passado, a região da Ponte de Pedra ficou fora de todas essas demarcaçóes e dentro de uma propriedade particular. Hoje, os Haliti lutam pela reconquista desse local, considerado sagrado para seu povo. Há uma área identificada e delimitada de dezessete mil hectares (17.000 ha), que compreende os municípios de Campo Novo dos Parecis e São José do Rio Claro, abrangendo a região do córrego Caititu, do Rio Ponte de Pedra e a confluência destes com o Ribeirão Roncador. Entretanto, a demarcação e o registro permanecem inconclusos.

Há muitos lugares com os sinais que resguardam a ação de Wazare, os quais se situam em locais atualmente privatizados. Mesmo não estando mais presentes fisicamente, permanecem sendo lembrados na imagem mental, reatualizando a memória histórica de suas criaçóes. Assim foi ouvido por um outro homem Haliti, da Aldeia Seringal: perto do Itamarati, lá na Chapada, tem pau que escorrega macaco. É a sucupira. Tem um poço, uma lagoa. É um lugar sagrado. Ali é o começo da geração Warere. Desse poço, só podiam beber pessoas da familia Warere. Esse poço, hoje em dia, não existe mais. A fazenda derrubou essa árvore sucupira e acabou com o poço. Antigamente, se outra familia bebesse dessa água, morreria. Wazaré é o Deus que fez todas as cabeceiras, as árvores e que dividiu e espalhou os Haliti (Campo Novo dos Parecis-MT, 1996).

Retomando Benjamin (2001), a ideia da sobrevida aqui se imprime. Acontecem contínuas alteraçóes na realidade do mundo sobre a terra que não apagaram a agência do Wazare, seja física ou imageticamente. $\mathrm{O}$ mundo de fato não é cópia idêntica do original, os Haliti experimentam a alteridade de maneira específica, resguardando a sua historicidade.

As práticas socioculturais contingentes na vida cotidiana do povo Haliti não são idênticas às do passado, mas também não são superaçóes dele. Conforme Bhabha (2005), são alteraçóes a partir da interação com uma multiplicidade de histórias que são descontínuas entre si e que envolvem momentos temporais e espaços geográficos descontínuos. Houve 
relação com diversos segmentos sociais de diferentes períodos históricos, desde meados do século XIX até os tempos atuais, que trouxeram elementos novos que foram conhecidos, interpretados e incorporados conforme seus interesses. A forma de traduzir tais vivências não se orientou para uma história linear e contínua. Permanece inscrita a descontinuidade destas, criando algo novo que não tem semelhança com nenhum dos elementos envolvidos.

Isso é retratado no fato de que várias famílias do povo Haliti possuem seringais, lavoura mecanizada de arroz, caçam com espingarda e bicicleta, usam roupa passada com ferro a brasa de carvão, têm relógio pendurado nas paredes trançadas com palha de buriti, vendem abanador de pó feito com rabo de ema nas cidades vizinhas, fazem parceria com empresa privada para o cultivo de soja dentro da terra indígena, cobram pedágio na estrada que corta a sua terra, têm contas bancárias, mas permanecem trazendo a caça para a regiáo da flecha sagrada, dividindo-a posterior mente ao benzimento dela, fazendo festa para o dono da mandioca antes de colher e consumir o cultivo da roça, assim como as cabaças permanecem cheias como oferta aos donos, com quem permanecem interagindo nessa rede de relaçáo social amplamente expandida.

Entretanto, a caça e a pesca estão continuamente diminuindo, e a fome impóe-se como realidade para várias comunidades. A expansão do agronegócio e do latifúndio, correlacionada aos valores e às concepçóes positivistas e orientadas à produção da semelhança, são explicaçóes para esse acontecimento.

O uso intensivo de agrotóxicos e o desmatamento na margem de nascentes e rios produzem contaminação irreversível da água, ar e solo, seca e erosão dos rios e de suas nascentes, afetando a qualidade de vida dos animais, peixes, aves e pessoas.

Fazendeiros e empresários, mesclados aos vereadores, deputados estaduais, federais, senadores e a outros cargos do poder executivo são agentes no desmatamento do cerrado, em especial na região da Chapada dos Parecis. Articulados entre si, destroem os sinais das criaçóes de seres humanos e não humanos que vivem sobre e sob a terra. Ignorantes da realidade dos outros, preservam a condição de mundos separados e distantes, recusando-se ainda a atravessar a ponte e a arriscar-se à experiência de uma relação. 


\section{Referências}

ASSAD, Talal. The Concept of Cultural Translation in British Social Anthropology. In: CLIFFORD, James; MARCUS, George (Ed.). Writing Culture. The Poetics and Politics of Ethonography. Berkeley: University of California, 1986.

BASSNETT, Susan \& TRIVED, Harish. Introduction: of colonies, cannibals and vernaculars. In: Postcolonial Translation. Theory and Practive. London and New York: Routledge, 1999.

BENJAMIN, Walter. A tarefa-renúncia do tradutor. In: HEIDERMANN, Werner (Org.). Clássicos da Teoria da Tradução. Florianópolis: Universidade Federal de Santa Catarina, 2001. v. 1.

BERMAN, Antoine. Translation and the trials of the foreign. In: VENUTI, Lawrence (Org.). The Translation Studies Reader. London \& New York: Routledge, 2000.

BHABHA, Homi. Como o novo entra no mundo: o espaço pós-moderno, os tempos pós-coloniais e as provaçôes da tradução cultural. In: O Local da Cultura. Belo Horizonte: Ed. UFMG, 2005.

BORTOLETTO, Renata. Morfologia social Paresi: uma etnografia das formas de sociabilidade em um grupo Aruak no Brasil Central. Dissertação de Mestrado. Campinas: Unicamp, 1999.

CAMPOS, Haroldo de. A língua pura na teoria da traduçâao de Walter Benjamin. Revista USP. São Paulo, v. 33, 1997.

COSTA, Romana Maria Ramos. Cultura e contato: Um Estudo da Sociedade Paresi no Contexto do Contato das Relações Interétnicas. Dissertação de Mestrado. UFRJ, Rio de Janeiro, 1985.

DERRIDA, Jacques. Torres de Babel. Belo Horizonte: Ed. UFMG, 2002.

LAGES, Susana Kampff. A tarefa do tradutor. In: Walter Benjamin. Tradução e Melancolia. São Paulo: Edusp, 2002.

LATOUR, Bruno. Les machines. In: La Science en Action. Paris: Éditions la Découverte, 1989.

LATOUR, Bruno. Jamais Fomos Modernos. Ensaio de Antropologia Simétrica. Rio de Janeiro: Editora 34, 1994.

MACHADO, Maria Fátima Roberto. Indios de Rondon: Rondon e as linhas telegráficas na visão dos sobreviventes Waimaré e Kaxiniti, grupos paresi. Tese de Doutorado. Rio de Janeiro: UFRJ, 1994. 
BRASIL. Ministério da Justiça. Portaria MJ, no. 3078 de 27/09/2010. DOU: 28109\2010. DF, 2010.

RICOEUR, Paul. The paradigm of translation. In: On Translation. London and New York: Routledge, 2006.

RONDON, Cândido Mariano da Silva. História Natural. Etnografia pelo General Cândido Mariano da Silva Rondon. Anexo n ${ }^{\circ}$. Rio de Janeiro: Imprensa Nacional, 1947.

RUBEL, Paul \& ROSMAM, Abraham. Introduction: Translation and Anthropology. In: Translating Cultures. Perspectives on translation and anthropology. New York: Berg, 2003.

STEINER, George. The Hermeneutic Motion. In: VENUTI, Lawrence (Org.). The Translation Studies Reader. London \& New York: Routledge, 2000.

Resumo: Este artigo desenvolve-se a partir do mito de origem do povo Haliti, mais conhecido como Paresi, localizado na região da Chapada dos Parecis, Noroeste de Mato Grosso, Brasil. Tem-se como objetivo compreender como se inscreve na narrativa mítica a maneira de esse povo se relacionar com o outro, contemplando conjuntamente as suas experiências com o não indígena, abrangendo, neste particular, os períodos históricos das frentes de expansôes socioeconômicas relacionadas aos ciclos da borracha e do agronegócio, bem como o período do Projeto das Linhas Telegráficas de Rondon. A reflexão está apoiada nas discussões teóricas sobre tradução desenvolvidas por vários autores, destacando-se Walter Benjamin, Jacques Derrida, Homi Bhabha e Bruno Latour. É reconhecido que a reflexão aqui apresentada é uma tradução dedicada a compreender modos de viver relações com o outro.

Palavras-chave: mito, Paresi, história, alteridade, tradução.

\section{The Stone Bridge, crossing into other worlds}

Abstract: This article is developed from the myth of origin of the people Haliti, better known as Paresi, located in the Chapada dos Parecis, northwest of Mato Grosso, Brazil. It has been aimed at understanding how the mythic narrative fits the way that people relate to each other, contemplating their experiences together with the non-indigenous, covering this particular historical periods of expansions socioeconomic fronts related to the cycles of rubber and agribusiness, as well as the period of the Project Telegraph Rondon. The reflection is supported on theoretical discussions about translation developed by several authors, notably Walter Benjamin, Jacques Derrida, Homi Bhabha and Bruno Latour. It is recognized that the discussion presented here is a translation dedicated to understanding ways of living relationships with others.

Key words: myth, Paresi, history, otherness, translation.

Recebido em: 29/02/2012

Aprovado em: 25/05/2012 